\title{
The Relationship between Public Health and the Use of Excessive Cell Phone in Girl Students of Paramedical of Behbahan College
}

\author{
Zeinab Rajabzadeh ${ }^{1}$ \\ Gholamreza Shahbazi Moghadam1* \\ Seyedeh Sahar Hosseini ${ }^{1}$ \\ ${ }^{1}$ Behbahan Faculty of Medical Sciences, Behbahan, Iran
}

Doi:10.5901/mjss.2016.v7n4s1p289

\begin{abstract}
The aim of this study was to investigate the relationship between public health and the use of excessive cell phone in Paramedical college of Behbahan. The aim of this study population consists of descriptive and correlational study included all girl students of Paramedical of Behbahan college which 100 ones were randomly selected. The tool of research was consist of General Health Questionnaire (GHQ) and questionnaire was excessive use of mobile phones. (jenar et al, 2007). The obtained results from data analysis showed that the public health aspects of excessive cell phone use is a significant positive relationship exist on.
\end{abstract}

Keyword: Public health, excessive use of cell phone, girl students, Paramedical college of Behbahan

\section{Introduction}

One of the major events for young students, university admission is primarily due to the students' specific situations such as being away from family, entering the large collections and tense like universities, high volume, long courses, intensive competition, and prone to the cause of the mental and physical health, and requires the attention of researchers and responsible. (Tahmasebian et al, 2011) Health has many dimensions physical, mental, spiritual, emotional and social that Physical aspects of health because the full function of all organs of the body is normally easier and Conversely, mental health is much harder to be understood However many factors affect their health One of these factors is the use of mobile phones . (Rabani et al, 2012) Excessive use of mobile phones in some cases the normal life of a person and even moods and psychological interference and clutter buildup. Excessive use of that reduce the time its excessive use family and social interaction occurs. All these problems in a person's field of depression makes extensive. On the other hand, depression and excessive use of mobile phones, both are unhealthy way of life. (Kami bipo \& Sogira, 2005)

Students have a bunch of mobile phone users are exposed to injuries from overuse of these devices are located. They may also have problems in school with the educational, economic, social and cultural changes they face. These issues such as depression, stress and anxiety occurs. (Kalgen, 1993) Use of mobile traumatic a situation that is characterized by widespread use of mobile phones is an intellectual occupation. (Nadery,1388 According to jenaro, 2007) Medical research results that alternately about the physical effects of mobile phones is not conducted in favor of this means of communication. The normative and mental health are key issues in psychiatry and mental health of practical and theoretical aspects of the overall concept of health. (Sadok, 2007) According to the blok belonging to obsessivecompulsive are disorders and Next as a public health issue in South Korea and other Asian countries has become. (Bakhtiari \& Adibeik, 2010) Based on Ahronbog three categories predictor of addiction include : Exclusion ( negative physiological and psychological response to the lack of material behavior ), Loss of control ( using excessive iterations ) and agility (Activity dominant thoughts and behaviors ). In this study have been with heavy use of relation of mobile phone -with conflict and Electra version While conscientiousness and high nervousness, excessive use of SMS to predict. Mobile self-esteem predicts behavior. People with low self-esteem, and to a greater extent problematic use of mobile phones have reported. (aherberg, 2008) Evidence has shown that frequent use of mobile phones associated with other behavioral patterns, including awake at night and employment to exchange short messages and As well as emotional dependence that is created in the minds of users. So that these people believe that without the use of mobile phones are not able to continue living. These findings supportive negative impact of excessive use of mobile phone and its negative 
effect on physical and psychological health of users. (kamibpod \& Sogira, 2005) Addiction -like behaviors mobile phone for work and social life of people is a serious problem. these addicts if their mobile phone is not their near, depressed, broke and lonely Sensation. (brain, 2007) Research shows that the relative correlation between depression and anxiety are related to the number of messages in a day. (Naderi, 2011,acorting to Rochart,2008) Now the mobile phone on the physical health of children and adolescents has been emphasized and the results of research conducted in this area also supports this. (Letkeb, 2008) So do research in relation to public health witth excessive use of mobile phones among the youth, especially students are important and can help prevent serious injuries.

\section{Research Method}

Current research procedure is regarded as one of unity description. It was done In order to study the relationship between general health and cellphone overuse among students of paramedical faculty of Behbahan.

General health quiz (GHQ): a test with self-performance multiple characteristics that is designed for studying nonschizophrenia disorders found in different situations of the society. General health quiz was first regulated by Goldberg (1972). The main quiz includes 60 questions, but shortened forms with 12, 28 and 30 questions have been used in different fields too. According to researchers, those different forms of general health quiz have got high validity and proficiency and the proficiency of a form with 12 questions almost is equal to that of 60 questions. The GHQ form with 28 questions was performed on a model group in Amsterdam with the scale of emotional balance and Amsterdam's biography by Goldberg and Hiller 12 (1979), Hodiamont and et al (1988) and in each one coefficient of 60\% unity was reported. To check the validity and endurance of the test in Persian Society, Taqavi (1380) performed 167 general health quizzes (form of 28 questions) in a research. In this research, endurance of the general health quiz was checked based on three re-examination, bisectionally and Cronbach's Alpha and 70\%, 93\% and $90 \%$ were resulted, respectively. The coeval validity of GHQ was reported by means of coeval performing of Midlacks Hospital quiz (55\%). Unity coefficients between subtests of this quiz and the final result were fairly reported $72 \%$ to $87 \%$. This is a sample of questions in this quiz: "have you felt that you are in a good physical condition from the past month?"

Cellphone overuse scale (COS): this quiz was collected based on to 10 psychological index from the guide of diagnose and classification of mental disorders. This scale includes 23 questions and is according to the form of Lycret spectrum answers (6 items; never, almost never, sometimes, often, almost always, always). Higher scores reflect overuse. In checking the normalization of this scale on 782 students, endurance of the test was reported 0.903 due to Cronbach's Alpha. The endurance of scale was calculated by means of re-examination of scale $r=0.714$ which was normal in the surface of 0.001 . this is a sample of questions: "do you feel restless or worried when you don't use cellphone?"

The research quizzes (GHQ and COS) were given to the students. At the beginning, students were assured that this quiz is exclusively academic, answers will be kept confidential and there is need to write the name.

The data of quizzes after completion were put into the software spss. for analysis of the information, methods of descriptive statics, Pierson's unity test and the software spss have been used.

\section{Findings}

Table 1: Descriptive information: shows number, mean, standard deviation, minimum and maximum public health status and the use of mobile phone.

Table 1: Public health variables and descriptive statistics using mobile phone

\begin{tabular}{|c|c|c|c|c|c|}
\hline maximum & minimum & average & Standard deviation & number & Statistics \\
\hline 22 & 8 & 12.63 & 3.35 & 100 & variable \\
\hline 21 & 7 & 13.66 & 3.91 & 100 & Anysical \\
\hline 23 & 7 & 13.40 & 3.48 & 100 & Social function \\
\hline 25 & 7 & 10.80 & 4.07 & 100 & Depression \\
\hline 88 & 32 & 50.50 & 11.13 & 100 & Health of gemeral \\
\hline 97 & 22 & 48.96 & 15.23 & 100 & Using from mobile phone \\
\hline
\end{tabular}

As you can see from Table 1, the highest public health measures related to anxiety variable (sleep disorder) and 
depression variable is the lowest. Pearson correlation coefficient was used to test the hypothesis that both hypotheses are with presented.

Table 2: The correlation coefficient for the relationship between public health and use the mobile phone

\begin{tabular}{|c|c|c|}
\hline Significance level & The correlation coefficient of pierson & Statistics \\
\hline \multirow{2}{*}{$<0.001$} & \multirow{2}{*}{0.391} & Variable \\
\cline { 3 - 3 } & The criterion variable : use of mobile phone \\
\hline
\end{tabular}

As can be seen from Table 2 between general health with excessive use of mobile phones there is the hypothesis is confirmed.

Table 3: The correlation coefficient for the relationship between anxiety and sleep disorders and the use of mobile phones

\begin{tabular}{|c|c|c|}
\hline Significance level & The correlation coefficient of pierson & statics \\
\hline \multirow{2}{*}{0.003} & \multirow{2}{*}{0.323} & The criterion variable : use of mobile phone \\
\cline { 3 - 3 } & & Predictor variables : anxiety, sleep disorder \\
\hline
\end{tabular}

As can be seen from Table 3 subscale anxiety and sleep disorder with excessive use of mobile phones there is the hypothesis is confirmed.

Table 5 : The correlation coefficient for the relationship between depression and the use of mobile

\begin{tabular}{|c|c|c|}
\hline Significance level & The correlation coefficient of pierson & statics \\
\hline \multirow{2}{*}{$<0.001$} & \multirow{2}{*}{0.379} & The criterion variable : use of mobile phone \\
\cline { 3 - 3 } & & Predictor variables : Depression \\
\hline
\end{tabular}

As can be seen from Table 5 between the subscales depression and excessive use of mobile phones there is the hypothesis is confirmed. $(p<0.001$ and $r=0.379)$

Table 6: The correlation coefficient for the relationship between physical symptoms and using a mobile phone

\begin{tabular}{|c|c|c|}
\hline Significance level & The correlation coefficient of pierson & statics \\
\hline \multirow{2}{*}{0.141} & \multirow{2}{*}{0.163} & variable \\
\cline { 2 - 3 } & The criterion variable : use of mobile phone \\
\hline
\end{tabular}

As can be seen from Table 6 between the subscales of physical symptoms with excessive use of mobile phones there is the hypothesis is rejected. (05/0 $p>0.05$ and $r=0.163)$

\section{Discussion and Conclusion}

The main aim of this study was to investigate the relationship between general health and disposal of mobile phone among female students is excessive. The results showed that the students' general health and usage of the phone there is a significant positive relationship. This means that people who have more general health is in danger of cell phone use. In this research measures items such as public health aspects such as depression, anxiety and etc. So the top score of depression and anxiety and to show that it is represents in public health risk (low health). In making this finding can be due argue that students fill leisure or other reasons to escape from loneliness and turn mobile phone So that they can provide the vacuum and thus when brought to the shelter by their health put at stake. It should be noted that the results were Narva etal (2003) , Roswell (2003) and Yassami Nejhad et al (1391) is consistent. The second hypothesis showed 
that the relationship between physical symptoms with no cell phone use Because researchers like Kizyli et al (2003) concluded that listen for users when talking on a cell phone near the source of the electric field and away from the antenna to listen to just a few centimeters. This distance can be very dangerous and the physical symptoms affect people. But despite the researchers in this study no relationship found between physical symptoms using a mobile phone So this result is consistent with findings of Kambio \& Sogira (2005) Beylux \& Anderlinden, D. Akarmuns, schi Zermaten(2007) is inconsistent.

The third hypothesis showed that between anxiety and impaired students with the use of mobile phones there . as this means the increasing use of mobile phones, anxiety and sleep disorders are also more students. So that Azoki (2008 ) noted that young people who are extreme and substance use any phone short messages have high levels of anxiety . As well as linden and Rochart (2008) also reported that the number of messages a day with anxiety, depression, relationship. It can be stated that the student class are adolescents and young people are turning to new technologies such as mobile phones. Unfortunately, if you use the wrong style of mobile phone time and free time outside of classes and internships are busy with your mobile phone and by calling or texting communicate with others and this is strong evidence that the number of calls and messages when the overshoot is caused consternation for, and whether or not they are suffering from anxiety and insomnia.

The fourth hypothesis has been shown that the positive relationship between social function with excessive use of mobile phones there is a significant Schneider as a result of the findings and Hastrvf 1979 (according to the Yassami race) is consistent. So that excessive use of mobile phones can cause harm to an individual function at home and work environment. For example, if the device is overused in the workplace causes suspicion and in some cases thorny other health care organizations. In addition, at home, when people use the device too Many programs and everyday things forgotten or impatience doing and most importantly, student use of these devices in the classroom is a distraction for him, Researchers like Atadokht et al (1392) in recognition of speech, also showed that the use of mobile traumatic There is a negative correlation with academic performance and motivation to reduce them .

The fifth hypothesis too could be shown between depression and the use of mobile phones there is a significant positive relationship. It can be said that when depressed people may turn to mobile phones or vice versa with the improper use of mobile phone causes of depression in these patients. kervat, Patterson, Lanmark and colleagues (1998) found that the use of new communication technologies, social relations in real mode and reduce data loss due to the wellbeing of loneliness, depression and isolation.

\section{Reference}

Atadokht, A,. Hamidi far, V., Mohammadi, E., (2013), Use and type of mobile phone use among high school students and its relationship with academic performance and achievement motivation, Journal of School Psychology, 3(2),122-136

Azuki, T, (2008); Todays mobile phone users: cusers current and Emergine Trends, (WWW.Azuki sys-tems.com)

Brian, $r$, tilhamsh , yong, $t,(2007)$; «Evelompent of a scal to mesure problem use of short mmessage servies : the sms problem use diagnostic questionnaire», Cyber psychologe \& behaviour , 841-844.

Callaghan, p , morrisseyj, (1998); «Social support and heal the :a review », journal o advanced nursing, 18(6),203-210

Ehrerberg, a , juckess, whtek, walsh s, (2008); «personality and self esteem as predictors of yong peoples», techonloge use cyber psychobgy \& behaviour, $11,739-741$.

Fancheniy, (2004); symptoms of problematic cpu in adolescents, journal of adolescences. (www.sciencedirect.com/science)

Gol Mohammadian, M., Yasami Nejhad, p.,(2011), Validity and reliability of the scale of mobile phone use in approved research deputy of Islamic Azad university students Dezful Azad 6.trh

Jenaro, C., Flores, N., Gomez, M., Gonzlez-Gil, F., \& Caballo, C. (2007); « Problematic Internet and cell-phone use: Psychological, behavioral, and health correlates», Addiction Research \& Theory, 15(3), 309-320.

Kamabppu and sugure , k , kamibeppa and h. Supiueal (2005) impact o mobile phone on junior hogh school students behaior \& 121 123 alltest via cross ref/view recor in scopus cited by in scopus.

Kamibeppa , k \& sugiure , h , (2005); «impact of the mobile phone on junor high school students friends hips in the tokeyo», metropolitan area cybel pasycholge \& behaviior \&, $12,121-130$.

Kamibeppuok, S, Suginra, H, (2005); «I mpact of the mobile phone on junior high school student friendships in the Tokyo metropolitan area», cyber Psychology \& Behavior ,8 (2), 121-130.

Kizilay,A, Ozturan ,O, Erdem, T, Kalcioyla, M.T, Miman, M.C, (2003); «Effect of chronic exposure of electromagnetic fields from mobile on hearing in rats», Auris Nasas Larynx, 3(3). 239-450.

Kruat, R, Patterson, M, Landmark, V, Kiesler, S, Mukopadhyaay, T \& Scherlist, W,(1998); « Internet paradox, A Social technology that reduces Social involvement and Psychological well being», American Psychologist , 53(9), 1017-1031.

Letgeb, $n$ \& wei , r , (2000); «More than just talks on the more : uses and gratification of the cellcular phone», journalsm and mass communication quarterly, 1,36-41

Mahmoodi Bakhtiari, Behrooz, Adi Beig, Arezo, (2010). Mobile as written media, discourse studies of short message texts humor 
Persian, Journal of research of Zaban and Adabiaiat Farsi,15,175-198

Naderi, F., \& Haghshenas, F. (2010), Validation of Scale of Robert (BIS-11) and the relationship Takashgary and loneliness, with the use of mobile phones on male and female students Azad University of Ahvaz, Master's thesis, General Psychology, Azad University of Ahvaz.

Rabbani, H., Mahfouz pour, R., Kamelia, (2002); Captain physical health status of male students in Sarvan, journal research of Medical Sciences of Zahedan (Physician East)

Sadokeb, J., \& Sadokeb, V.A., (2004); Summary Psychiatry, Translated by Hasan Rafie \& Farzin Rezaie, first publish, Arjmand press, Tehran, Iran

Taghavi, S.M.R., (2001); a survey of Validity and credibility of the General Health Questionnaire (GHQ), Journal of psychology, 20,381398

Tahmasebian, H., Arefi, M., Jahangiri, M., Heidari Asl, H.. (2011); The relationship between loneliness and mental health in students of Razi University, Regional conference on child and adolescent psychological Islamic Azad University of Kermanshah 